\title{
Attitudes of relatives of mucopolysaccharidosis type III patients toward preconception expanded carrier screening
}

\author{
Stephanie C. M. Nijmeijer ${ }^{1} \cdot$ Thirsa Conijn $^{1,4} \cdot$ Phillis Lakeman $^{2} \cdot$ Lidewij Henneman $^{3} \cdot$ Frits A. Wijburg $^{1}$ • \\ Lotte Haverman ${ }^{4}$
}

Received: 3 January 2020 / Accepted: 28 April 2020 / Published online: 1 June 2020

(c) The Author(s), under exclusive licence to European Society of Human Genetics 2020

\begin{abstract}
Preconception expanded carrier screening (ECS) aims to detect carrier couples of autosomal recessive (AR) disorders before pregnancy in order to increase reproductive autonomy of prospective parents. Genetic knowledge and knowledge gained from experience influence decision making on participation in genetic testing and understanding carrier test results. In this study we assessed whether parents and relatives of patients with the severe AR condition mucopolysaccharidosis type III (MPS III), who are expected to have genetic and experiential knowledge, have more positive attitudes toward ECS than the Dutch reference group. Parents of all MPS III patients known to the Dutch expert center were invited to participate and asked to invite first and second degree relatives. The online questionnaire started with an educational text, and assessed attitudes toward ECS, genetic knowledge and perceived MPS III severity. Results were compared with the Dutch population. Parents and relatives of MPS III patients $(n=159)$ scored higher on the genetic knowledge test and perceived MPS III as more severe compared with the general Dutch population $(n=781)$. Parents and relatives reported to be more likely to participate in ECS $(84.3 \%$ and $62.5 \%$, respectively) compared with the public $(31 \%)(p<0.001)$. Being a relative of a MPS III patient was the strongest variable in the regression analyses for intended ECS participation. Our results show that genetic knowledge influences ECS decision making. Therefore, appropriate information on ECS and genetic counseling is needed to enable prospective parents from the general population, including relatives of patients with severe hereditary disorders, to make informed decisions.
\end{abstract}

Supplementary information The online version of this article (https:// doi.org/10.1038/s41431-020-0648-2) contains supplementary material, which is available to authorized users.

Frits A. Wijburg

f.a.wijburg@amsterdamumc.nl

1 Amsterdam UMC, Pediatric Metabolic Diseases, Emma Children's Hospital and Amsterdam Lysosome Center "Sphinx", University of Amsterdam, Meibergdreef 9, Amsterdam, The Netherlands

2 Amsterdam UMC, Department of Clinical Genetics, Amsterdam Reproduction and Development Research Institute, University of Amsterdam, Meibergdreef 9, Amsterdam, The Netherlands

3 Amsterdam UMC, Department of Clinical Genetics, Amsterdam Reproduction and Development Research Institute, Vrije Universiteit Amsterdam, De Boelelaan 1117, Amsterdam, The Netherlands

4 Amsterdam UMC, Psychosocial Department, Emma Children's Hospital, University of Amsterdam, Meibergdreef 9, Amsterdam, The Netherlands

\section{Introduction}

Preconception expanded carrier screening (ECS) aims to detect carrier couples of autosomal recessive (AR) disorders who face a $25 \%$ risk of having an affected child in each pregnancy, in order to facilitate informed reproductive decision making. Most of these couples are unaware of this risk, as carrier status does not affect one's health, and in most cases the birth of an affected child is highly unexpected [1]. Carrier screening is preferably offered before a pregnancy, in order to increase the reproductive options for prospective parents [1,2]. There are more than 1300 AR disorders, ranging from mild to severe, and it is estimated that up to 2 in 100 couples in the general population is a carrier couple of a severe AR disorder [1, 3, 4]. Targeted ECS panels for specific AR disorders have been successfully introduced for populations at high risk, such as individuals of Ashkenazi Jewish descent [5] and genetically isolated communities [6]. More recently, universal ECS panels have been made available to the general public, predominantly offered by commercial companies [7]. In the Netherlands, two academic medical centers, 
Amsterdam UMC and the University Medical Center Groningen, now offer universal preconception ECS to the general public who have no a priori risk for being a carrier couple based on ancestry and/or a consanguineous relationship. However, these panels are not reimbursed by health insurance companies [8, 9]. Typically, the disorders included in these two panels are severe disorders with a childhood onset resulting in significant intellectual and/or physical disability and/or a limited life expectancy due to lack of a sufficiently effective disease-modifying treatment, as is advised in the field of preconception carrier screening [1]. The majority of these disorders are inborn errors of metabolism (IEMs), such as mucopolysaccharidosis (MPS) type III, Tay-Sachs disease and Krabbe disease [8, 9]. The IEMs included in ECS panels generally have a progressive course. Previous studies in the USA, Sweden and the Netherlands have investigated the opinions of the general population toward universal preconception ECS and reported that between $30 \%$ and $34 \%$ of the respondents would consider to use preconception ECS [1012]. The study by Ong et al., conducted in Australia, showed that genetic knowledge, i.e., baseline knowledge on genetics, is instrumental in influencing ECS participation [13]. Several other studies also underpinned that genetic knowledge and experiential knowledge, i.e., the objective and subjective knowledge gained from experience with the disease, influence and shape decision making on participating in genetic testing and understanding of carrier test results [14-18]. In a recent study by our group on the attitudes of the general Dutch population toward ECS [19], 31\% of the respondents would consider ECS. However, familiarity with a genetic disease was not associated with intended ECS participation. This may be explained by the diverse spectrum of supposedly genetic diseases mentioned by the participants, including multifactorial disorders such as diabetes mellitus and eczema. Studies in patients with an AR or X-linked disorder and their families show that the majority is in favor of preconception population carrier screening for the specific disorder in their family: $75 \%$ of affected families with spinal muscular atrophy (SMA) [20], 81-86\% of cystic fibrosis (CF) patients and their parents [21], $83 \%$ of caregivers of a child with fragile $X$ syndrome [22], and 75\% of hemophilia patients [23]. MPS III (Sanfilippo disease) is an example of a disorder generally included in ECS panels, as it is characterized by progressive neurodegeneration resulting in cognitive decline, behavioral problems, loss of motor functions and early demise [24]. Parenting a child with MPS III strongly impacts the well-being of parents, resulting in anxiety, depression and post-traumatic stress symptoms [25]. We hypothesized that genetic and experiential knowledge on the nature of a disorder generally included in universal preconception screening panels and its potential impact on the patient and the family leads to a more positive attitude toward ECS. We therefore assessed the attitudes of parents and relatives of MPS III patients toward preconception ECS and compared these outcomes to attitudes of people of reproductive age from the general Dutch population.

\section{Methods}

\section{Participants and procedures}

Parents of all MPS III patients known to the MPS III expert center of the Amsterdam UMC, location Academic Medical Center, were invited by letter to participate in this online questionnaire study. All mothers and fathers who agreed to participate were asked individually to invite their first and second degree relatives (parents, siblings, and/or healthy children $\geq 18$ years of age) to participate as well and provided us with contact details after consent. Contact details were available to one researcher (SCMN) and were stored in a coded database. Participants received an e-mail with a personal link to the online questionnaire. The purpose of the study, and its anonymous data management were explained to all potential participants preceding the start of the questionnaire. Previously collected attitudes of people from the general Dutch population toward preconception ECS were used as comparator [19]. This group, here defined as 'reference group', comprises 781 participants in the reproductive age (18-45 years). A full explanation of data collection procedures of the reference group is presented in Nijmeijer et al. [19]. Ethical approval for this study and the previous study with the reference group was waived by the Medical Ethics Committee of the Amsterdam UMC, the Netherlands, as this is an anonymous questionnaire study.

\section{Sociodemographic characteristics}

The sociodemographic characteristics age, gender, educational level, religious beliefs, marital status, if the participant was considering a (future) pregnancy or currently pregnant (partner of self) were collected from the three groups (parents, relatives, and the reference group). Two questions were asked to investigate the familiarity with carrier screening: (1) 'Have you ever heard of a carrier test before this questionnaire?' and (2) 'Have you ever taken a carrier test?' followed by an open text field to allow to substantiate their answer.

\section{Educational text}

Prior to the start of the questionnaire, a brief educational text including information on (1) the principle of AR inheritance; (2) the fact that an ECS test is available in the Amsterdam UMC and includes 50 severe AR childhood disorders; and (3) the clinical features of MPS III as an example of the types of disorders included in the test (Supplementary material A). This educational text was identical to the one used for the reference group [19]. 


\section{Genetic knowledge test}

After reading the educational text, a brief genetic knowledge test (on AR inheritance and ECS) consisting of seven items on a three-point scale were used to verify if the educational text was correctly understood (incorrect, correct and I do not know) (Supplementary material B).

\section{Perceived MPS III severity}

Perceived severity of MPS III was evaluated with two questions on a five-point Likert scale: 'I believe that MPS III is a severe disease' and 'I believe that the life expectancy of MPS III patients is very bad (severe patients often die before reaching adulthood)' (Supplementary material B).

Questions from these two domains were also asked in our previous study but the results were not included in the publication on attitudes of the general Dutch population toward ECS [19]. In the current study, these data are used to assess whether relatives of MPS III patients have more genetic knowledge and perceive MPS III as more severe (experiential knowledge) than the reference group.

\section{ECS questionnaire}

The current study (Supplementary material C) uses the ECS questionnaire which was also used in Nijmeijer et al. [19]. The questionnaire was developed in consensus by members of the research team (including experts in pediatric metabolic diseases, psychology, genetics and health sciences) based on items from existing questionnaires used for assessing attitudes toward ECS among the Ashkenazi Jewish population [26] and toward carrier screening for $\mathrm{CF}$ [27]. The questionnaire includes the following six domains: $I$. Intention to participate in ECS. II. Level of agreement on feelings toward ECS (e.g., 'I find it positive that all couples considering a (future) pregnancy can take the carrier test for 50 severe hereditary disorders'). III. Perceived benefits of (A) and barriers against ECS (B), and freedom-of-choice statements (C). IV. Most important reasons in favor of ECS and against ECS. $V$. Perceived social influences when considering ECS. VI. Perceived personal consequences of ECS; considerations regarding test results of ECS, perceived consequences as a carrier (couple), and perceived reproductive choices as a carrier couple. Domain $I$ consisted of a multiple-choice question. Answers from domain II were measured using a semantic five-point differential scale with seven adjective word pairs: negativepositive, undesirable-desirable, frightening-nonfrightening, unwise-wise, non-reassuring-reassuring, unethical-ethical, and logical-illogical. The level of agreement on the domains $I I I, V$, and $V I$ was given on a five-point Likert scale $(1=$ totally disagree/unimportant to $5=$ totally agree/important).
The answers from domain $I V$ were measured by choosing a maximum of two arguments out of a list of arguments.

\section{Statistical analyses}

The Statistical Package for Social Sciences (SPSS) version 25.0 for Windows was used for all statistical analyses (SPSS, Inc., Chicago, IL, USA). First, items from the test on genetic knowledge were converted to binary items $(0=$ incorrect/I do not know, $1=$ correct $)$ in order to calculate a total sum score ranging from 0 to 7 . Second, items on five-point scales were converted to binary items $(0=($ totally $)$ disagree/do not disagree and do not agree/ (very) low/not low, not high, $1=$ (totally) agree/(very) high). Third, the outcomes on the word pairs (domain II) were summarized into three answer categories: $1=$ (totally) disagree, $2=$ do not disagreeldo not agree to $3=$ (totally) agree. Answers on the genetic knowledge test and the perceived severity of MPS III (experiential knowledge) were compared between parents and relatives of MPS III patients, and the reference group.

Descriptive analyses were used to report on sociodemographic characteristics and the answers on the questionnaire. To compare sociodemographic characteristics and attitudes of the three groups (parents, relatives of MPS III patients, and the reference group), Chi-Square Tests were used for categorical variables and Independent Sample $T$-tests and Mann-Whitney $U$ tests for continuous variables. Multivariate logistic regression analyses were performed to investigate whether being a parent or a relative of a MPS III patient, age, gender, educational level, marital status, religion, and considering a (future) pregnancy were associated with outcomes on the following questions: 'Intention to participate in ECS' (domain I), 'I find it ethically acceptable that all couples considering a (future) pregnancy can take the carrier test' (domain II), 'ECS can prevent suffering for future parents' (domain III), 'as a carrier couple, I would consider in vitro fertilization (IVF) with embryo selection' (domain $V I)$ and, 'as a carrier couple, I would consider in prenatal diagnostics' (domain VI). Standardized regression coefficients $(\beta)$ of 0.1 are considered small, 0.3 as medium and 0.5 as large. For predictor variables that are binary coded, 0.2 can be considered small, 0.5 as medium and 0.8 as large [28]. $p$ values $<0.05$ were considered statistically significant.

\section{Results}

\section{Participants}

Parents of 57 MPS III patients were invited to participate in this study of which parents of 9 patients declined 
Table 1 Sociodemographic characteristics.

\begin{tabular}{|c|c|c|c|c|c|c|c|}
\hline & Parents $^{\mathrm{a}}$ & & Relatives $^{\mathrm{b}}$ & & Reference $^{\mathrm{c}}$ & & \\
\hline & $n=58$ & $\%$ & $n=101$ & $\%$ & $n=781$ & $\%$ & $p$ \\
\hline Age in years; mean (SD) & $48.36(11.76)$ & & $51.40(17.40)$ & & $31.18(7.33)$ & & $<0.001$ \\
\hline $18-24$ & & & 8 & 8 & 151 & 19 & $<0.001$ \\
\hline $25-34$ & 1 & 2 & 14 & 14 & 374 & 48 & \\
\hline $35-45$ & 22 & 38 & 14 & 14 & 256 & 33 & \\
\hline $46-90$ & 34 & 59 & 65 & 64 & & & \\
\hline Female gender & 33 & 57 & 62 & 62 & 379 & 49 & 0.020 \\
\hline Educational level $^{\mathrm{d}}$ & & & & & & & 0.003 \\
\hline Low & 11 & 19 & 21 & 21 & 77 & 10 & \\
\hline Intermediate & 24 & 41 & 30 & 30 & 321 & 41 & \\
\hline High & 23 & 40 & 50 & 50 & 383 & 49 & \\
\hline Religious beliefs & & & & & & & 0.185 \\
\hline No & 30 & 52 & 53 & 53 & 341 & 44 & \\
\hline Yes & 27 & 47 & 48 & 48 & 418 & 54 & \\
\hline I do not want to say & 1 & 2 & & & 22 & 3 & \\
\hline Marital status & & & & & & & 0.005 \\
\hline Single & 5 & 9 & 18 & 18 & 198 & 25 & \\
\hline In a relationship/married & 53 & 91 & 83 & 82 & 583 & 75 & \\
\hline Considering a (future) pregnancy & & & & & & & $<0.001$ \\
\hline No & 56 & 97 & 79 & 78 & 461 & 59 & \\
\hline $\mathrm{Yes}^{\mathrm{e}}$ & 2 & 3 & 22 & 22 & 320 & 41 & \\
\hline 'Currently pregnant (partner or self) ${ }^{\mathrm{f}}$ & 2 & 3 & 2 & 2 & 20 & 3 & \\
\hline $\begin{array}{l}\text { Have you ever heard of a carrier test before this } \\
\text { questionnaire? }\end{array}$ & & & & & & & $<0.001$ \\
\hline No & 23 & 40 & 42 & 58 & 604 & 77 & \\
\hline Yes & 35 & 60 & 59 & 42 & 177 & 23 & \\
\hline Have you ever taken a carrier test? & & & & & & & $<0.001$ \\
\hline No & 35 & 60 & 65 & 64 & 756 & 97 & \\
\hline Yes & 23 & 40 & 36 & 36 & 25 & 3 & \\
\hline
\end{tabular}

Characteristics were compared by Independent Sample $T$-test for continuous variables (mean age) and ChiSquare Tests for categorical variables (other). Significant differences at $p<0.05$ are printed in bold. Percentages were rounded-off.

andividual parents (mothers and fathers) of MPS III patients, both deceased and alive.

${ }^{\mathrm{b}}$ First and second degree family members of MPS III patients.

${ }^{c}$ Reproductive-aged people from the general Dutch population [19].

${ }^{\mathrm{d}}$ Educational level low: primary education, lower vocational education, lower and middle general secondary education. Intermediate: middle vocational education, higher secondary education, pre-university education. High: higher vocational education, university.

Distribution of educational levels in the Netherlands: $30 \%$ low, $40 \%$ intermediate and $30 \%$ high.

${ }^{\text {e}}$ Participants considering a (future) pregnancy. Answers comprised of the following: 'I have no children at the moment but I would like to have children', 'I have children and my partner and I would like to have more children', I am/my partner is currently pregnant', or 'I would have liked to have children but I remained childless'.

${ }^{\mathrm{f}}$ Percentage participants that is currently pregnant of those participants that consider a (future) pregnancy. participation or could not be reached. In total, 58 out of 68 parents $(85 \%)$ of 46 MPS III patients participated; 48 out of $57(84 \%)$ parents of living MPS III patients and 10 out of $11(91 \%)$ parents of deceased MPS III patients. Some families consisted of more than one MPS III patient or of a single parent household. As parents were asked to invite their relatives at their discretion, no response rate could be calculated. In total, 101 relatives participated.

\section{Sociodemographic characteristics}

Parents and relatives were significantly older, more often female, more often in a relationship, and considered less often a (future) pregnancy compared with the reference group. A lower proportion of respondents in the reference group had a low educational level compared with parents and relatives of MPS III patients. The frequency of having religious beliefs was similar in the different groups (Table 1). 


\section{Genetic knowledge test}

Parents and relatives of MPS III patients scored significantly higher on the total sum score of the genetic knowledge test (range 0-7) compared with the reference group (respectively median 7 (range $3-7, n=58$ ) and 6 (range $2-7, n=101$ ) vs. median 5 (range $0-7, n=781))(p<0.001)$.

\section{Perceived severity of MPS III}

Parents and relatives of MPS III patients more often agreed with the statement that MPS III is a severe disease (respectively $85 \%$ and $95 \%$ ) compared with the reference group $(72 \%, p<0.001)$ and more often agreed that MPS III patients have a very bad life expectancy (respectively $86 \%$ and $94 \%$ ) compared with the reference group $(75 \%, p<0.001)$.

\section{ECS questionnaire}

\section{Intention to participate in ECS}

Parents and relatives of MPS III patients were more likely to (probably or certainly) take a (similar) preconception ECS test (respectively $84.3 \%$ and $62.5 \%$ ) compared with the reference group (people in the reproductive age from the Dutch general population) $(31 \%, p<0.001)$. Twelve percent of the parents and $21 \%$ of the relatives reported that they had previously taken a similar preconception carrier test compared with $1 \%$ of the reference group $(p<0.001)$.

\section{Level of agreement on feelings toward ECS in general and on personally considering ECS}

The level of agreement of parents of MPS III patients and the reference group on feelings toward ECS in general (Fig. 1a) and when personally considering ECS (Fig. 1b) differed significantly between the two groups, in favor of ECS for the parents, on all word pairs. Level of agreement of relatives are not shown to keep the manuscript concise, but were in line with those of parents of MPS III patients.

\section{Perceived benefits of and barriers against ECS, and freedom-of-choice statements}

Parents and relatives of MPS III patients more often agreed with the statement that the use of ECS can avoid suffering for the entire family (respectively $88 \%$ and $86 \%$ ) compared with the reference group $(68 \%, p<0.001)$ (Table $2 a)$. In addition, parents and relatives less often agreed that ECS can lead to anxiety (respectively 19\% and $21 \%$ ) compared with the reference group $(39 \%, p<0.001)$ (Table $2 b$ ). Furthermore, the majority $(66 \%, 65$ and $55 \%$ of parents, relatives and the reference group respectively) agreed that
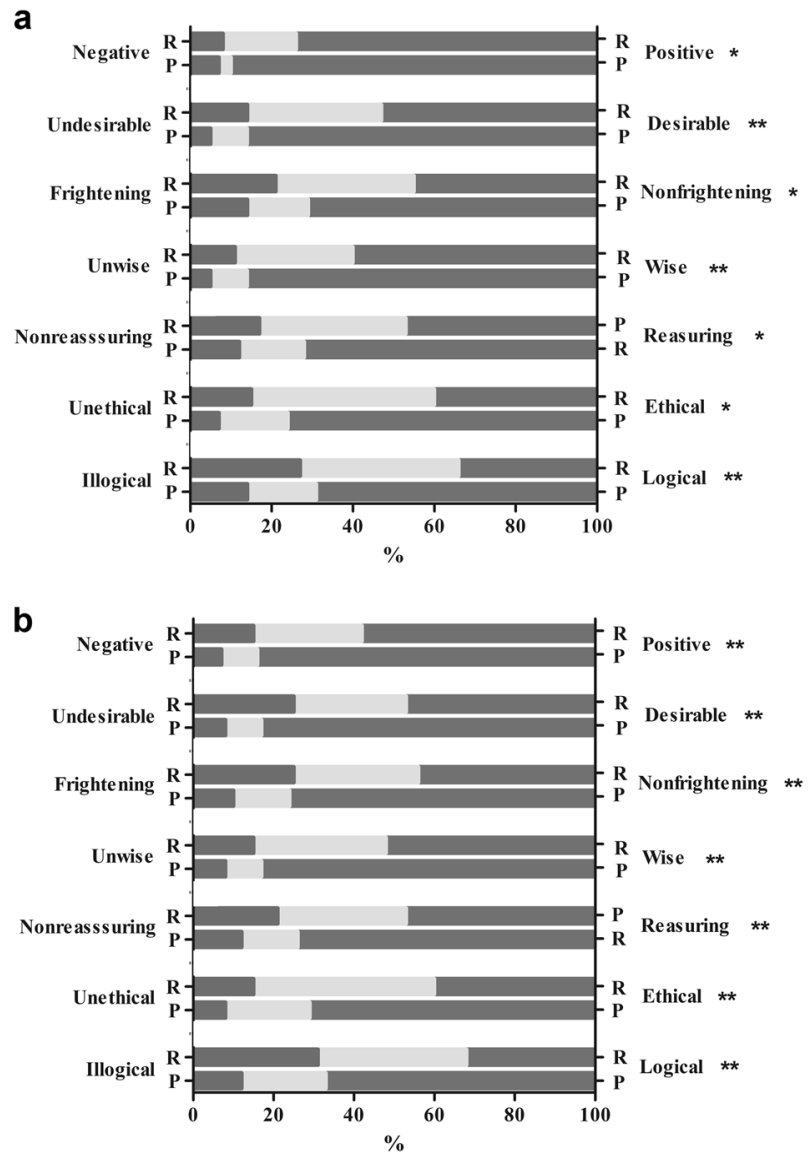

Fig. 1 Level of agreement on feelings toward ECS in general and on personally considering ECS. a Level of agreement on feelings toward ECS in general. Questionnaire domain II. The figure illustrates the level of agreement of the reference group $(\mathrm{R} ; n=781)$ and parents of MPS III patients (P; $n=58)$ on seven feelings in response to the question: 'That all couples considering a (future) pregnancy can take the carrier test for 50 severe hereditary disorders, I find' The red bars represent the percentage of participants who (totally) agreed with the words on the left side of the figure. The gray bars represent the percentage of participants with a neutral opinion toward the word pairs. The green bars represent the percentage of participants who (totally) agreed with the words on the right side of the figure. $* p<0.05$, ** $p<$ 0.001 by using Chi-Square Tests. b Level of agreement on feelings when personally considering ECS. Questionnaire domain II. The figure illustrates the level of agreement of the reference group (R; $n=$ 781) and parents of MPS III patients $(\mathrm{P} ; n=58)$ on seven feelings in response to the question: 'That I personally can take the carrier test for 50 severe hereditary disorders, I find'. The red bars represent the percentage of participants who (totally) agreed with the words on the left side of the figure. The gray bars represent the percentage of participants with a neutral opinion toward the word pairs. The green bars represent the percentage of participants who (totally) agreed with the words on the right side of the figure. ${ }^{*} p<0.05, * * p<0.001$ by using Chi-Square Tests (Color figure online).

the carrier test should be offered to every couple that wants to have children but parents and relatives more often agreed that every couple that wants to have children must take the carrier test $(35 \%$ and 39\%) compared with the reference group $(22 \%, p<0.001)$ (Table $2 c)$. 
Table 2 Statements regarding perceived benefits of and barriers against ECS and freedom-of-choice statements.

\begin{tabular}{|c|c|c|c|c|}
\hline & $\begin{array}{l}\text { Parents }^{\mathrm{a}} \\
n=58 \\
\%\end{array}$ & $\begin{array}{l}\text { Relatives }^{\mathrm{b}} \\
n=101 \\
\%\end{array}$ & $\begin{array}{l}\text { Reference }^{\mathrm{c}} \\
n=781 \\
\%\end{array}$ & $p$ \\
\hline \multicolumn{5}{|l|}{ A. Perceived benefits of ECS } \\
\hline $\begin{array}{l}\text { Offering the carrier test avoids much suffering for the } \\
\text { entire family }\end{array}$ & 88 & 86 & 68 & $<0.001$ \\
\hline The carrier test can avoid suffering for future parents & 86 & 86 & 67 & $<0.001$ \\
\hline The carrier test can prevent costs for the family & 52 & 57 & 57 & 0.702 \\
\hline The carrier test can prevent costs for the society & 60 & 59 & 49 & 0.045 \\
\hline $\begin{array}{l}\text { The results of a carrier test can help in choosing a partner } \\
\text { B. Perceived barriers against ECS }\end{array}$ & 3 & 11 & 7 & 0.211 \\
\hline $\begin{array}{l}\text { The carrier test creates too high expectations of the birth of a } \\
\text { healthy child }\end{array}$ & 35 & 34 & 44 & 0.068 \\
\hline Offering a carrier test leads to anxiety & 19 & 21 & 39 & $<0.001$ \\
\hline $\begin{array}{l}\text { The carrier test will be the first step in developing a } \\
\text { perfect child }\end{array}$ & 16 & 20 & 32 & 0.003 \\
\hline $\begin{array}{l}\text { Offering the carrier test can cause people to feel forced to } \\
\text { undergo testing }\end{array}$ & 7 & 16 & 29 & $<0.001$ \\
\hline $\begin{array}{l}\text { I am afraid of discrimination by carriers (for instance, by } \\
\text { insurance companies and the social environment) }\end{array}$ & 12 & 11 & 23 & 0.003 \\
\hline \multicolumn{5}{|l|}{ C. Freedom-of-choice statements } \\
\hline $\begin{array}{l}\text { The carrier test should be offered to every couple that wants to } \\
\text { have children }\end{array}$ & 66 & 65 & 55 & 0.052 \\
\hline $\begin{array}{l}\text { Every couple that wants to have children must take the } \\
\text { carrier test }\end{array}$ & 35 & 39 & 22 & $<0.001$ \\
\hline
\end{tabular}

Questionnaire part III: Agreement on statements.

Significant differences at $p<0.05$ are printed in bold.

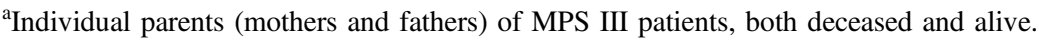

${ }^{b}$ First and second degree family members of MPS III patients.

${ }^{c}$ Reproductive-aged people from the general Dutch population [19].

\section{Most important reasons in favor of ECS and against ECS}

Out of eleven suggested reasons, the most frequently selected reason in favor of ECS for parents (50\%) and the reference group (47.2\%) was that they 'want to spare a child from a life with a severe hereditary disorder'. Relatives most frequently selected as reason in favor of ECS 'the presence of a hereditary disease in their family' (58.4\%) (Table 3a). Out of thirteen suggested reasons, the most frequently selected reason against ECS for parents and the reference group was that 'nobody in the family has one of these disorders' (37.9\% and $47.6 \%$, respectively). Relatives most frequently selected 'other' reasons against ECS (open text response) (42.6\%) (e.g., 'I have no desire to have any (more) children' or 'I would want to take the test') (Table 3b).

\section{Perceived social influences when considering ECS}

Compared with the reference group, parents and relatives of MPS III patients less often stated that the opinion from their surroundings (partner, parents, family, and friends) is important when considering ECS. Parents, relatives, and the reference group equally stated that the opinion of the religious community was important (Table 4a).

\section{Perceived personal consequences of ECS}

Considerations regarding test results (Table $4 \mathrm{~b})$ and perceived consequences as a carrier (couple) (Table 4c) all differed significantly between parents, relatives and the reference group. Parents and relatives of MPS III patients more often agreed with statements regarding perceived reproductive choices (Table 4d).

\section{Multivariate logistic regression analyses}

The results of the regression analyses are presented in Table 5. Being a parent or relative of a MPS III patient was the strongest variable associated with intended ECS participation. Parents and relatives were also more likely to believe that offering ECS is ethically acceptable, to believe 
Table 3 Reasons in favor of and against ECS.

\begin{tabular}{|c|c|c|c|c|}
\hline & $\begin{array}{l}\text { Parents }^{\mathrm{a}} \\
n=58 \\
\%\end{array}$ & $\begin{array}{l}\text { Relatives }^{\mathrm{b}} \\
n=101 \\
\%\end{array}$ & $\begin{array}{l}\text { Reference }^{\mathrm{c}} \\
n=781 \\
\%\end{array}$ & $p$ \\
\hline \multicolumn{5}{|l|}{ A. Reasons in favor of ECS } \\
\hline $\begin{array}{l}\text { I want to spare my child from a life with a severe hereditary } \\
\text { disorder }\end{array}$ & 50 & 36.6 & 47.2 & 0.111 \\
\hline For my children (when they want to have children) & 37.9 & 38.6 & 14.5 & $<0.001$ \\
\hline A hereditary disorder occurs in my family & 27.6 & 58.4 & 17.0 & $<0.001$ \\
\hline I want to prepare myself for a child with one of these disorders & 13.8 & 8.9 & 23.8 & 0.001 \\
\hline $\begin{array}{l}\text { I believe I have a great chance of being a carrier } \\
\text { B. Reasons against ECS }\end{array}$ & 13.8 & 14.9 & 16.6 & 0.782 \\
\hline Nobody in the family has one of these disorders & 37.9 & 21.8 & 47.6 & $<0.001$ \\
\hline Other $^{\mathrm{d}}$ & 31.0 & 42.6 & 10.2 & $<0.001$ \\
\hline $\begin{array}{l}\text { I have taken a carrier test for only the disorder for which I have } \\
\text { an increased risk }\end{array}$ & 8.6 & 17.8 & 4.7 & $<0.001$ \\
\hline I am afraid of the test results & 8.6 & 10.9 & 15.7 & 0.170 \\
\hline I do not believe I have a great chance of being a carrier & 6.9 & 8.9 & 20.4 & $<0.001$ \\
\hline
\end{tabular}

Questionnaire part IV: the top 5 most frequently selected reasons by parents in favor of and against ECS in order of frequency

Significant differences at $p<0.05$ are printed in bold.

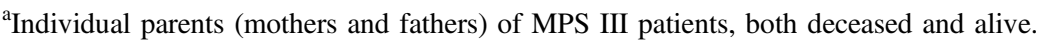

${ }^{\mathrm{b}}$ First and second degree family members of MPS III patients.

${ }^{c}$ Reproductive-aged people from the general Dutch population [19].

${ }^{\mathrm{d}}$ For example; I would take the ECS test or I do not want (any more) children. that ECS prevents suffering for future parents, as a carrier couple to consider IVF with embryo selection and prenatal diagnostics. Age was the only variable not associated with any of the outcome variables.

\section{Discussion}

The objective of this study was to investigate the attitudes of parents and relatives of patients with the severe, progressive and ultimately fatal AR disorder MPS III, toward universal preconception ECS and to compare this to the Dutch general population. We hypothesized that MPS III parents and relatives are more in favor of preconception ECS due to their genetic and experiential knowledge. This study indeed showed that parents $(84 \%)$ and relatives $(63 \%)$ are significantly more likely to participate in ECS than the participants from the general population (31\%). Being a parent or relative of a MPS III patient turned out to be the strongest variable in the regression analyses for intended ECS participation, even when controlled for sociodemographic factors.

As hypothesized, relatives of MPS III patients scored significantly better on the genetic knowledge test compared with the participants from the general population and might explain the more positive attitudes toward ECS of relatives, as was previously described by Ong et al. [13].
Relatives of MPS III patients more often believed that MPS III is a severe disease compared with the reference group. This is not surprising as MPS III is a ultra-rare disorder [24, 29] and participants from the general population therefore likely had no (experiential) knowledge on this disease. The experiential knowledge of the relatives on the type of diseases generally included in ECS panels also might explains their overall positive attitudes toward ECS. A Belgian study investigating attitudes toward ECS of adult patients with $\mathrm{CF}$ and their parents, showed that $59 \%$ of the patients and $53 \%$ of the parents would want to get tested before a pregnancy for conditions other than CF [21]. This seems lower than the results of our study, suggesting that the perceived severity of the diseases included in ECS impacts on its uptake as patients with CF have a significant longer life expectancy than MPS III patients and do not have progressive cognitive decline.

The primary goal of offering ECS is not reaching the highest uptake but to increase reproductive autonomy among prospective parents [1]. Although increasing autonomy is generally regarded as positive, there have been some concerns [30]. The existence of ECS panels may lead to the feeling that it is a moral duty to participate or a moral obligation to avoid an affected child [2]. Moreover, concerns have been raised that human dignity, reflecting tolerance of the disabled, may be challenged as ECS programs 
Table 4 Statements regarding perceived personal consequences of ECS.

\begin{tabular}{llll} 
Parents $^{\mathrm{a}}$ & Relatives $^{\mathrm{b}}$ & Reference $^{\mathrm{c}}$ & \\
$n=58$ & $n=101$ & $n=781$ & \\
$\%$ & $\%$ & $\%$ & $p$ \\
\hline
\end{tabular}

A. Perceived social influences when considering ECS

The opinion of my partner is important in making the decision about the carrier test

The opinion of my parents is important in making the decision about the carrier test

The opinion of my family is important in making the decision about the carrier test

\section{9}

31

22

The opinion of my friends is important in making the decision about the carrier test

The opinion of my religious community is important in making the decision about the carrier test

B. Considerations regarding test results of ECS

I would find it difficult if my child would be affected by one of the 50 disorders

The results of a carrier test can help me in making decisions about having children

If I do not participate, I am afraid I will regret it if my child is affected with one of the 50 disorders

Offering a carrier test takes away the spontaneity of having children

If I do not participate, I am afraid I will regret it later

C. Perceived consequences as a carrier (couple)

By preventing the birth of child with a severe hereditary disorder, a lot of suffering can be prevented

It is important that the birth of a child with a severe hereditary disorder can be prevented

If I were a carrier, I would find it difficult to inform my family members about their increased risk of being a carrier

I am afraid people will look differently at me when they know I am a carrier

I would feel less healthy as a carrier

D. Perceived reproductive choices as a carrier couple

I would consider an examination of the fetus during pregnancy (prenatal testing by chorionic villus 83 sampling)

I find it important that carrier couples can prepare themselves for the birth of a child with a severe hereditary disorder

As part of a carrier couple, I would consider in vitro fertilization (IVF) with embryo selection

If my partner and I are a carrier couple, I would decide not to have (more) children

I would take the risk and not take any action (the child is born as he or she is)

I would consider termination of the pregnancy if the child is affected with one of the 50 disorders

I am against abortion of a child with one of these 50 disorders

Questionnaire part V and VI: Agreement on statements in order of frequency.

Significant differences at $p<0.05$ are printed in bold.

andividual parents (mothers and fathers) of MPS III patients, both deceased and alive.

${ }^{b}$ First and second degree family members of MPS III patients.

${ }^{c}$ Reproductive-aged people from the general Dutch population [19].

could change the view on human value [31]. Parents and relatives in this study were nevertheless overall positive about ECS. Surprisingly, the absence of AR disorders in the family was the most frequently selected reason against ECS by parents of MPS III patients, as was also shown for the general population [19], and mentioned as reason not to participate in $\mathrm{CF}$ carrier screening in Australia by pregnant women and their partners, and couples prior to conception [32]. This shows that even parents and relatives of patients with a very severe AR disorder appear to estimate their chances of being a carrier as low when there is no medical history in the family. This emphasizes the importance of comprehensive genetic counseling. ECS providers should not assume that people with experiential knowledge because of a known AR genetic condition in the family will extend this knowledge about carrier status to their understanding of the risk of being a carrier for other genetic conditions. Moreover, as previously suggested, awareness of ECS and knowledge about genetic diseases in the general population should be increased to ensure successful implementation [16].

This study has some limitations. First, this study included parents and relatives of MPS III patients and research showed that parenting a MPS III child has great impact on the well- 


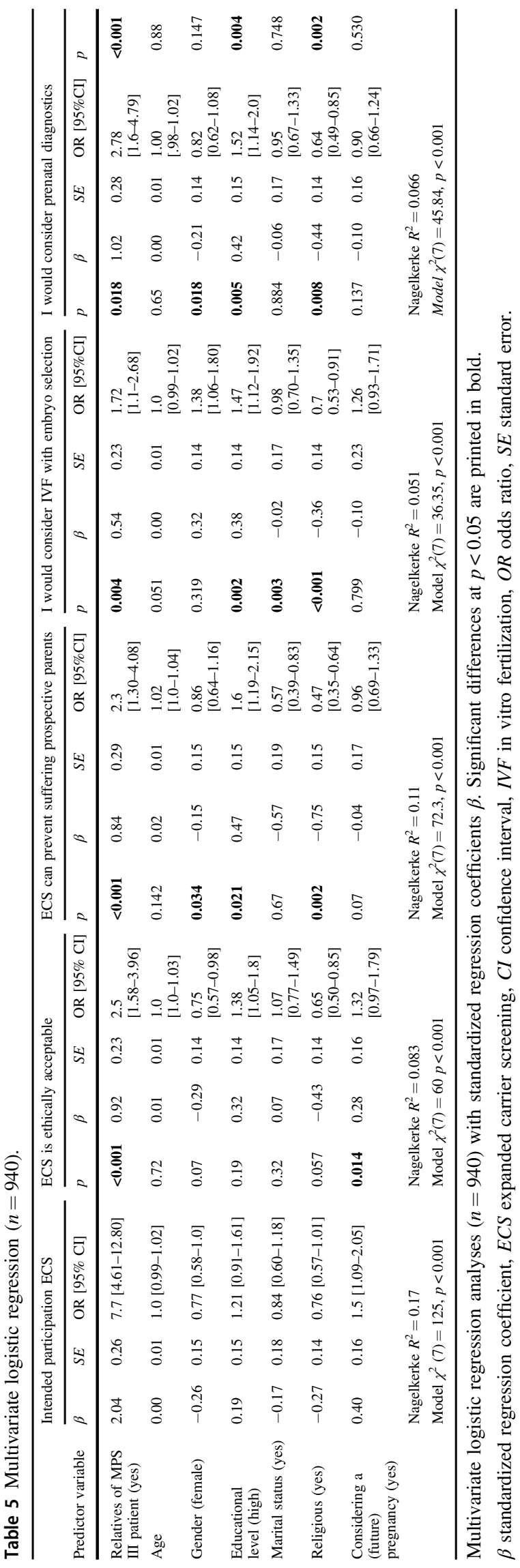

being of parents [25, 33, 34]. The impact of some of the other disorders included in ECS panels may be less severe which may have resulted in an overestimation of the potential uptake of ECS by affected families by our study. Second, as recruitment of relatives was done by parents of MPS III patients, we were not informed about reasons for declining participation (e.g., ethical or religious beliefs) or the number of relatives that were invited to participate. Therefore, the attitudes of our participants may not fully reflect the attitudes of all families of MPS III patients. Third, sociodemographics differed between relatives of MPS III patients and participants from the general population. These characteristics, however, were included in the logistic regression analyses and the effect of being a relative is the strongest variable associated with intended ECS participation. Although parents and relatives were significantly older than the reference group, age was not associated with any of the outcome variables. We verified this by analyzing intended ECS participation separate in the age group 35-45, which was significantly higher among parents (85\%) and relatives (80\%) compared with the reference group.

In conclusion, this study demonstrates a higher positive attitude of persons with genetic and experiential knowledge of a severe and yet untreatable AR disorder toward universal preconception ECS compared with participants of the Dutch general population. The fact that the most mentioned reason against participating in ECS was the absence of AR disorders in the family, suggest that people estimate their chances of being a carrier as low when there is no medical history in the family, even despite the fact that participants were informed that everyone is carrier for one or several AR disorders. As informed decision making is based on genetic knowledge in addition to personal values [35], we emphasize the importance of appropriate information and counseling in order to enable informed reproductive decision making about ECS. This is not only important for the general population, but also for families with experiential and genetic knowledge to avoid misconceptions on this complex matter.

Funding This study was funded by grants from the private foundations Zabawas, Zeldzame Ziekten Fonds, and Kinderen en Kansen, the Netherlands. The authors confirm independence from the sponsors; the content of this article has not been influenced by the sponsors.

\section{Compliance with ethical standards}

Conflict of interest All authors are affiliated to a hospital that offers ECS in a non-commercial setting. The authors declare that they have no conflict of interest.

Publisher's note Springer Nature remains neutral with regard to jurisdictional claims in published maps and institutional affiliations. 


\section{References}

1. Henneman L, Borry P, Chokoshvili D, Cornel MC, van El CG, Forzano F, et al. Responsible implementation of expanded carrier screening. Eur J Hum Genet. 2016;24:e1-e12.

2. van der Hout S, Dondorp W, de Wert G. The aims of expanded universal carrier screening: Autonomy, prevention, and responsible parenthood. Bioethics. 2019;33:568-76.

3. Ropers HH. On the future of genetic risk assessment. J Commun Genet. 2012;3:229-36.

4. Sankaranarayanan K. Ionizing radiation and genetic risks IX. Estimates of the frequencies of mendelian diseases and spontaneous mutation rates in human populations: a 1998 perspective. Mutat Res. 1998;411:129-78.

5. Klugman S, Gross SJ. Ashkenazi Jewish screening in the twentyfirst century. Obstet Gynecol Clin N Am. 2010;37:37-46.

6. Mathijssen IB, Henneman L, van Eeten-Nijman JM, Lakeman P, Ottenheim CP, Redeker EJ, et al. Targeted carrier screening for four recessive disorders: high detection rate within a founder population. Eur J Med Genet. 2015;58:123-8.

7. Chokoshvili D, Vears D, Borry P. Expanded carrier screening for monogenic disorders: where are we now? Prenat Diagnosis. 2018;38:59-66.

8. Amsterdam UMC. ECS list of diseases; 2020. https://www.amc.nl/w $\mathrm{eb} /$ dragerschapstesten/dragerschapstesten/de-dragerschapstest.htm.

9. UMCG. ECS list of diseases; 2020. https://www.umcg.nl/ IDocuments/LAB-F024602E_UMCG_Conditions_and_genes_ included_in_UMCG_preconception_screening_test.pdf .

10. Plantinga M, Birnie E, Abbott KM, Sinke RJ, Lucassen AM, Schuurmans $\mathrm{J}$, et al. Population-based preconception carrier screening: how potential users from the general population view a test for 50 serious diseases. Eur J Hum Genet. 2016;24:1417-23.

11. Ekstrand Ragnar M, Tyden T, Kihlbom U, Larsson M. Swedish parents' interest in preconception genetic carrier screening. Upsala J Med Sci. 2016;121:289-94.

12. Pereira N, Wood M, Luong E, Briggs A, Galloway M, Maxwell RA, et al. Expanded genetic carrier screening in clinical practice: a current survey of patient impressions and attitudes. J. Assist Reprod Genet. 2019;36:709-16.

13. Ong R, Howting D, Rea A, Christian H, Charman P, Molster C, et al. Measuring the impact of genetic knowledge on intentions and attitudes of the community towards expanded preconception carrier screening. J Med Genet. 2018;55:744-52.

14. Archibald AD, McClaren BJ. Perceived relevance of genetic carrier screening: observations of the role of health-related life experiences and stage of life in decision making. J Commun Genet. 2012;3:47-54.

15. Etchegary H, Potter B, Howley H, Cappelli M, Coyle D, Graham I, et al. The influence of experiential knowledge on prenatal screening and testing decisions. Genet Test. 2008;12:115-24.

16. Holtkamp KCA, Mathijssen IB, Lakeman P, van Maarle MC, Dondorp WJ, Henneman L, et al. Factors for successful implementation of population-based expanded carrier screening: learning from existing initiatives. Eur J Public Health. 2017;27:372-7.

17. Ioannou L, McClaren BJ, Massie J, Lewis S, Metcalfe SA, Forrest L, et al. Population-based carrier screening for cystic fibrosis: a systematic review of 23 years of research. Genet Med. 2014;16:207-16.

18. Boardman FK, Young PJ, Warren O, Griffiths FE. The role of experiential knowledge within attitudes towards genetic carrier screening: a comparison of people with and without experience of spinal muscular atrophy. Health Expect Int J Public Particip Health Care Health Policy. 2018;21:201-11.
19. Nijmeijer SCM, Conijn T, Lakeman P, Henneman L, Wijburg FA, Haverman L. Attitudes of the general population towards preconception expanded carrier screening for autosomal recessive disorders including inborn errors of metabolism. Mol Genet Metab. 2019;126:14-22.

20. Boardman FK, Young PJ, Griffiths FE. Population screening for spinal muscular atrophy: A mixed methods study of the views of affected families. Am J Med Genet Part A. 2017;173:421-34.

21. Janssens S, Chokoshvilli D, Binst C, Mahieu I, Henneman L, De Paepe A, et al. Attitudes of cystic fibrosis patients and parents toward carrier screening and related reproductive issues. Eur $\mathbf{J}$ Hum Genet. 2016;24:506-12.

22. Bailey DB Jr., Bishop E, Raspa M, Skinner D. Caregiver opinions about fragile X population screening. Genet Med Off J Am Coll Med Genet. 2012;14:115-21.

23. Boardman FK, Hale R, Gohel R, Young PJ. Preventing lives affected by hemophilia: a mixed methods study of the views of adults with hemophilia and their families toward genetic screening. Mol Genet Genomic Med. 2019;7:e618.

24. Valstar MJ, Ruijter GJ, van Diggelen OP, Poorthuis BJ, Wijburg FA. Sanfilippo syndrome: a mini-review. J Inherit Metab Dis. 2008;31:240-52.

25. Conijn T, Nijmeijer SCM, van Oers HA, Wijburg FA, Haverman L. Psychosocial functioning in parents of MPS III patients. JIMD Rep. 2018;44:33-41.

26. Holtkamp KC, van Maarle MC, Schouten MJ, Dondorp WJ, Lakeman P, Henneman L. Do people from the Jewish community prefer ancestry-based or pan-ethnic expanded carrier screening? Eur J Hum Genet. 2016;24:171-7.

27. Poppelaars FA, Henneman L, Ader HJ, Cornel MC, Hermens RP, van der Wal G, et al. Preconceptional cystic fibrosis carrier screening: attitudes and intentions of the target population. Genet Test. 2004;8:80-9.

28. Cohen J. Statistical power analysis for the behavioral sciences. Hillsdale, NJ: L. Erlbaum Associates; 1988.

29. Heron B, Mikaeloff Y, Froissart R, Caridade G, Maire I, Caillaud $\mathrm{C}$, et al. Incidence and natural history of mucopolysaccharidosis type III in France and comparison with United Kingdom and Greece. Am J Med Genet Part A. 2011;155a:58-68.

30. Chokoshvili D, Vears DF, Borry P. Reproductive autonomy in expanded carrier screening: more than meets the eye? Expert review of molecular diagnostics. 2018;18:993-94.

31. Matar A, Hansson MG, Hoglund AT. Values and value conflicts in implementation and use of preconception expanded carrier screening-an expert interview study. BMC Med Ethics. 2019;20:25.

32. McClaren BJ, Delatycki MB, Collins V, Metcalfe SA, Aitken M. 'It is not in my world': an exploration of attitudes and influences associated with cystic fibrosis carrier screening. Eur J Hum Genet. 2007; 16:435.

33. Grant S, Cross E, Wraith JE, Jones S, Mahon L, Lomax M, et al. Parental social support, coping strategies, resilience factors, stress, anxiety and depression levels in parents of children with MPS III (Sanfilippo syndrome) or children with intellectual disabilities (ID). J Inherit Metab Dis. 2013;36:281-91.

34. Kalkan Ucar S, Ozbaran B, Demiral N, Yuncu Z, Erermis S, Coker M. Clinical overview of children with mucopolysaccharidosis type III A and effect of Risperidone treatment on children and their mothers psychological status. Brain Dev. 2010;32:156-61.

35. Marteau TM, Dormandy E. Facilitating informed choice in prenatal testing: how well are we doing? Am J Med Genet. 2001;106:185-90. 